Original article

\title{
The immune response mediator genes polymorphic variants as predictors of the etanercept efficacy in juvenile idiopathic arthritis
}

\author{
Liliia Sh. Nazarova ${ }^{1}$, Ksenia V. Danilko ${ }^{1}$, Viktor A. Malievsky ${ }^{1}$, Akhat B. Bakirov ${ }^{1,2}$, Tatiana V. Viktorova ${ }^{1,3}$ \\ ${ }^{1}$ Bashkir State Medical University, Ufa, Russia \\ ${ }^{2}$ Ufa Research Institute of Occupational Health and Human Ecology, Ufa, Russia \\ ${ }^{3}$ Institute of Biochemistry and Genetics, Ufa, Russia
}

Received 2 December 2017, Revised 4 March 2018, Accepted 6 March 2018

(C) 2017, Nazarova L.S., Danilko K.V., Malievsky V.A., Bakirov A.B., Viktorova T.V.

C 2017, Russian Open Medical Journal

\begin{abstract}
Objective - The aim of the study was to investigate the relationship of the alleles and genotypes of the immune response mediator genes polymorphic loci (rs1800629, rs909253, rs16944, rs6822844, rs2104286, rs1800795, rs1800872, rs3087243, rs755622 rs28362491, rs2240336, rs2476601) with the etanercept efficacy in juvenile idiopathic arthritis (JIA) patients.

Material and Methods - The study included 39 JIA patients from Bashkortostan, Russia. Achieving the American College of Rheumatology Pediatric 70 (ACR Pedi 70) response was regarded as the presence of the response to etanercept (otherwise - as the absence), while achieving clinical remission on medication - as the sufficient response (otherwise - as the insufficient). Genotyping was performed using real-time polymerase chain reaction method.

Results - The predictors of an increased risk of the non-response to etanercept were the IL1B $\mathrm{rs}_{16944 * T T}\left(\mathrm{p}_{\mathrm{cor}}=0.023\right), N F K B 1$ rs28362491*II $\left(p_{c o r}=0.042\right)$ genotypes, and of the increased risk of the insufficient response to etanercept - the IL2RA rs2104286*AA $\left(p_{\text {cor }}=0.010\right), N F K B 1 \mathrm{rs} 28362491^{*} I I\left(p_{\text {cor }}=0.026\right)$ genotypes. The markers of the decreased risk of the non-response to etanercept were the IL1B rs16944*C ( $\left.p_{\text {cor }}=0.046\right), N F K B 1$ rs28362491*D ( $\left.p_{\text {cor }}=0.029\right)$ alleles, and of the decreased risk of the insufficient response to etanercept - the IL2RA rs2104286*AG genotype ( $\left.p_{\text {cor }}=0.049\right)$, IL2RA rs $2104286^{*} \mathrm{G}$ allele $\left(\mathrm{p}_{\text {cor }}=0.005\right)$.

Conclusion - In this study the association of the alleles and genotypes of the IL1B rs16944, IL2RA rs2104286, NFKB1 rs28362491 polymorphic loci with the etanercept efficacy in JIA patients was established.
\end{abstract}

Keywords: juvenile idiopathic arthritis, polymorphic loci, etanercept efficacy, predictors.

Cite as Nazarova LS, Danilko KV, Malievsky VA, Bakirov AB, Viktorova TV. The immune response mediator genes polymorphic variants as predictors of the etanercept efficacy in juvenile idiopathic arthritis. Russian Open Medical Journal 2018; 7: e0204.

Correspondence to Liliia Sh. Nazarova. Address: 47, Zaki Validi Str., Ufa, 450077, Russia. Phone: +7 (347) 273-58-75. E-mail: lilinaz19@mail.ru.

\section{Introduction}

Juvenile idiopathic arthritis (JIA) is the most common chronic rheumatic disease in children. The disease has no known cause, develops before the $16^{\text {th }}$ birthday and is characterized by persistent joint inflammation (longer than 6 weeks) [1-3].

It was shown, that JIA can lead to severe disability and is accompanied by a significant impairment in the quality of life of patients $[1,4]$. The important role in the preventing of JIA progression and patients disability is given to the timely appointment of an adequate therapy [5-8].

The main therapeutic agents for the JIA treatment include nonbiologic and biologic disease-modifying antirheumatic drugs (DMARDs), non-steroidal anti-inflammatory drugs (NSAIDs) and glucocorticosteroids, but their effectiveness is different in patients $[7,8]$. Therefore, it is an essential problem to find the predictors of the corresponding drugs efficacy, primarily for the DMARDs.

According to the American College of Rheumatology (ACR) recommendations for the treatment of JIA (2011), three tumor necrosis factor alpha (TNF $\alpha$ ) inhibitors (etanercept, adalimumab and infliximab) are recommended for the patients with an active arthritis and an insufficient response to the previous therapy [7].

Etanercept is a fully humanized soluble TNF receptor, which binds to TNF $\alpha$ and attenuates its effects [1]. Many cytokines, including TNF $\alpha$, lymphotoxin alpha (LT $\alpha)$, macrophage migration inhibitory factor (MIF), interleukins (ILS), and other regulatory molecules (such as cytotoxic T-lymphocyte associated protein 4 (CTLA4), nuclear factor kappa B subunit 1 (NF-kB1), protein tyrosine phosphatase, non-receptor type 22 (PTPN22)), as well as their genes polymorphisms are believed to play an important role in JIA pathogenesis and the disease progression [9-11]. The complex interaction of immune cells and mediators determines the specific clinical manifestations of JIA [12]. Thus, it can be assumed, that the changes in the regulatory molecules production and underlying genetic factors also affect the treatment effectiveness in JIA.

The aim of the study was to investigate the relationship of the alleles and genotypes of the immune response mediator genes polymorphic loci (TNFA rs1800629 (-308G>A), LTA rs909253 
(252A>G), IL1B rs16944 (-511C>T), IL2RA rs2104286, IL6 rs1800795 $(-174 \mathrm{G}>\mathrm{C}), \quad I L 10$ rs1800872 (-592C $>\mathrm{A})$, CTLA4 rs3087243, MIF rs755622 (-173G>C), NFKB1 rs28362491 (-94l>D), PADI4 rs2240336, PTPN22 rs2476601 (1858G>A)) and the intergenic region locus (IL2-IL21 rs6822844) with the etanercept efficacy in JIA patients.

\section{Material and Methods \\ Study design}

A case-control study was conducted. The study was approved by Local ethical committee of Bashkir State Medical University (Ufa, Russia). The parents of all patients signed the voluntary informed consent.

\section{JIA patients' characteristics}

Initially the whole JIA group included 330 children, who underwent examination and treatment in the Republican Children's Clinical Hospital (Ufa, Russia) in 2012-2017 years. The JIA diagnosis was established according to the International League of Associations for Rheumatology (ILAR) criteria [3].

The inclusion criteria to the JIA group were:

i) the presence of arthritis;

ii) the duration of arthritis more than 6 weeks;

iii) the patient's age less than 18 years;

iv) the onset of the disease at the age less than 16 years;

v) the absence of other diseases accompanied by arthritis;

vi) the signing of the voluntary informed consent by the patient's parents.

The exclusion criteria were

i) the duration of arthritis less than 6 weeks;

ii) the patient's age 18 years and over;

iii) the onset of the disease at the age 16 years and over;

iv) the established diagnosis of other diseases accompanied by inflammation in the joints;

v) the refusal to participate in the study by the patient or his parents.

The etanercept therapy (in a combination with methotrexate) was prescribed to 48 patients. The efficacy of the therapy was assessed in $39 \mathrm{JIA}$ patients aged 1.9 to 16.7 years. The mean age of 39 examined JIA patients was $8.4 \pm 3.7$ years, girls/boys ratio 1.8/1.0.

According to the ILAR criteria, the following JIA subtypes were presented: systemic arthritis $(n=3)$, rheumatoid factor positive polyarthritis $(n=3)$, rheumatoid factor negative polyarthritis $(n=16)$, persistent oligoarthritis $(n=1)$, extended oligoarthritis $(n=9)$, enthesitis related arthritis $(n=5)$, psoriatic arthritis $(n=1)$, undifferentiated arthritis $(n=1)$. The duration of the etanercept treatment was from 8 months to 7 years. Achieving the ACR Pediatric 70 (ACR Pedi 70 ) response was regarded as the presence of the response to etanercept (otherwise - as the absence), while achieving clinical remission on medication (Wallace et al., 2011) was regarded as the sufficient response to etanercept (otherwise as the insufficient) $[1,6,13-15]$. The presence of the response to etanercept was observed in 27 patients $(69.23 \%)$, while the sufficient response - in 21 patients (53.85\%).

\section{Experimental methods}

Deoxyribonucleic acid (DNA) was isolated from the lymphocytes of the whole blood samples using standard phenolchloroform method [16].

Twelve polymorphic loci (TNFA rs1800629 (-308G>A), LTA rs909253 (252A>G), IL1B rs16944 (-511C>T), IL2-IL21 rs6822844, IL2RA rs2104286, IL6 rs1800795 (-174G>C), IL10 rs1800872 (592C >A), CTLA4 rs3087243, MIF rs755622 (-173G>C), NFKB1 rs28362491 (-94I>D), PADI4 rs2240336, PTPN22 rs2476601 $(1858 \mathrm{G}>\mathrm{A})$ ) were examined. The genotyping was performed by real-time polymerase chain reaction (PCR) method using StepOnePlus ${ }^{\text {TM }}$ Real-Time PCR System (Applied Biosystems, USA) and commercial kits of sequence-specific primers and allelespecific probes (DNK-syntez, Russia).

\section{Statistical analysis}

The differences between the frequencies of the polymorphic loci alleles and genotypes in the studied groups were assessed using two-tailed Fisher's exact test in Microsoft Excel software. The odds ratio (OR) with 95\% Baptista-Pike confidence interval $(\mathrm{Cl})$ were calculated for the identified markers in Microsoft Excel and $R$ v.3.4.2 software [17].

The models of inheritance (co-dominant, dominant, recessive, over-dominant and log-additive) were studied by applying logistic regression in the SNPStats package [18]. The best model was the one with the lowest value of the Akaike information criterion (AIC). For the multiple comparison correction the permutation test with 10,000 permutes was performed in PowerMarker v.3.25 package $\left(p_{\text {cor }}\right)[19,20]$

In all the cases the results considered statistically significant at $\mathrm{p}<0.05$.

\section{Results}

\section{Genetic predictors of the non-response to etanercept}

As a result of the comparative analysis it was shown, that the IL1B rs16944*TT genotype was significantly more common and the IL1B rs $16944^{*} \mathrm{C}$ allele - significantly less common in JIA patients with the absence of the response to etanercept, than in those with its presence ( ${ }^{*} \mathrm{TT}: \mathrm{p}=0.025, \mathrm{p}_{\mathrm{cor}}=0.023, \mathrm{OR}=13.00,95 \% \mathrm{Cl} 1.57$ 163.39; ${ }^{*} \mathrm{C}: \mathrm{p}=0.044, \quad \mathrm{p}_{\mathrm{cor}}=0.046, \quad \mathrm{OR}=0.33,95 \% \mathrm{Cl} 0.13-0.89$ ) (Table 1). The best inheritance model was the recessive ( $\Pi \mathrm{vs}$. $C C+C T, p=0.014, O R=13.0,95 \% \mathrm{Cl} 1.26-133.64)$. Due to the small sample size, the stratification by sex was not carried out.

The NFKB1 rs28362491 polymorphism analysis showed that the frequency of the NFKB1 rs28362491*II genotype was significantly higher, and the frequency of the NFKB1 rs28362491*D allele was significantly lower in etanercept non-responders, than in responders ( ${ }^{*} \mathrm{II}: \mathrm{p}=0.043, \mathrm{p}_{\mathrm{cor}}=0.042, \mathrm{OR}=5.75,95 \% \mathrm{Cl} 1.28-22.26$; *D: $p=0.028, p_{\text {cor }}=0.029, O R=0.31,95 \% \mathrm{Cl} 0.12-0.85$ ) (Table 1). The log-additive model of inheritance was the best (2DD+ID vs. II, $\mathrm{p}=0.016, \mathrm{OR}=0.27,95 \% \mathrm{Cl} 0.08-0.87$ ).

For the other single nucleotide polymorphisms (SNPs) the differences were not significant $\left(p_{\text {cor }}>0.05\right)$. There was only a trend towards a lower frequency of the IL2RA rs2104286* $\mathrm{G}$ allele in JIA patients who did not respond to etanercept therapy in comparison with the responders $\left(p=0.092, p_{\text {cor }}=0.093\right)$. 
Table 1. The distribution of the genotypes and alleles of the studied polymorphic loci in relation to the response to etanercept in JIA patients

\begin{tabular}{|c|c|c|c|c|c|c|c|c|c|c|c|}
\hline \multirow{2}{*}{\multicolumn{2}{|c|}{ Polymorphic loci }} & \multicolumn{10}{|c|}{ Response to etanercept } \\
\hline & & \multicolumn{2}{|c|}{ Absence } & \multicolumn{2}{|c|}{ Presence } & \multirow[t]{2}{*}{ p-level } & \multicolumn{2}{|c|}{ Insufficient } & \multicolumn{2}{|c|}{ Sufficient } & \multirow[t]{2}{*}{ p-level } \\
\hline Gene, rs & Variants & Abs. & Freq. (\%) & Abs. & Freq. (\%) & & Abs. & Freq. (\%) & Abs. & Freq. (\%) & \\
\hline TNFA & GG & 12 & 100.00 & 23 & 85.19 & 0.292 & 16 & 88.89 & 19 & 90.48 & 1.000 \\
\hline \multirow[t]{4}{*}{ rs1800629 } & GA & 0 & 0.00 & 4 & 14.81 & 0.292 & 2 & 11.11 & 2 & 9.52 & 1.000 \\
\hline & $A A$ & 0 & 0.00 & 0 & 0.00 & 1.000 & 0 & 0.00 & 0 & 0.00 & 1.000 \\
\hline & G & 24 & 100.00 & 50 & 92.59 & 0.306 & 34 & 94.44 & 40 & 95.24 & 1.000 \\
\hline & A & 0 & 0.00 & 4 & 7.41 & 0.306 & 2 & 5.56 & 2 & 4.76 & 1.000 \\
\hline LTA & $\mathrm{AA}$ & 6 & 50.00 & 11 & 40.74 & 0.730 & 8 & 44.44 & 9 & 42.86 & 1.000 \\
\hline \multirow[t]{4}{*}{ rs909253 } & $A G$ & 5 & 41.67 & 14 & 51.85 & 0.731 & 8 & 44.44 & 11 & 52.38 & 0.751 \\
\hline & GG & 1 & 8.33 & 2 & 7.41 & 1.000 & 2 & 11.11 & 1 & 4.76 & 0.586 \\
\hline & $A$ & 17 & 70.83 & 36 & 66.67 & 0.797 & 24 & 66.67 & 29 & 69.05 & 1.000 \\
\hline & G. & 7 & 29.17 & 18 & 33.33 & 0.797 & 12 & 33.33 & 13 & 30.95 & 1.000 \\
\hline ILIB & $\mathrm{CC}$ & 2 & 16.67 & 11 & 40.74 & 0.269 & 4 & 22.22 & 9 & 42.86 & 0.307 \\
\hline \multirow[t]{4}{*}{ rs16944 } & $\mathrm{CT}$ & 6 & 50.00 & 15 & 55.56 & 1.000 & 10 & 55.56 & 11 & 52.38 & 1.000 \\
\hline & $\mathrm{TT}$ & 4 & 33.33 & 1 & 3.70 & 0.025 & 4 & 22.22 & 1 & 4.76 & 0.162 \\
\hline & C & 10 & 41.67 & 37 & 68.52 & 0.044 & 18 & 50.00 & 29 & 69.05 & 0.107 \\
\hline & $\mathbf{T}$ & 14 & 58.33 & 17 & 31.48 & 0.044 & 18 & 50.00 & 13 & 30.95 & 0.107 \\
\hline IL2-21 & $\mathrm{GG}$ & 11 & 91.67 & 19 & 70.37 & 0.228 & 14 & 77.78 & 16 & 76.19 & 1.000 \\
\hline \multirow[t]{4}{*}{ rs6822844 } & GT & 1 & 8.33 & 8 & 29.63 & 0.228 & 4 & 22.22 & 5 & 23.81 & 1.000 \\
\hline & $\mathrm{TT}$ & 0 & 0.00 & 0 & 0.00 & 1.000 & 0 & 0.00 & 0 & 0.00 & 1.000 \\
\hline & G & 23 & 95.83 & 46 & 85.19 & 0.261 & 32 & 88.89 & 37 & 88.10 & 1.000 \\
\hline & $\mathrm{T}$ & 1 & 4.17 & 8 & 14.81 & 0.261 & 4 & 11.11 & 5 & 11.90 & 1.000 \\
\hline IL2RA & $A A$ & 11 & 91.67 & 18 & 66.67 & 0.131 & 17 & 94.44 & 12 & 57.14 & 0.011 \\
\hline rs2104286 & AG & 1 & 8.33 & 7 & 25.93 & 0.394 & 1 & 5.56 & 7 & 33.33 & 0.049 \\
\hline & GG & 0 & 0.00 & 2 & 7.41 & 1.000 & 0 & 0.00 & 2 & 9.52 & 0.490 \\
\hline & A & 23 & 95.83 & 43 & 79.63 & 0.092 & 35 & 97.22 & 31 & 73.81 & 0.004 \\
\hline & G & 1. & 4.17 & 11 & 20.37 & 0.092 & 1 & 2.78 & 11 & 26.19 & 0.004 \\
\hline IL6 & $\mathrm{GG}$ & 7 & 58.33 & 12 & 44.44 & 0.501 & 10 & 55.56 & 9 & 42.86 & 0.527 \\
\hline rs1800795 & $\mathrm{GC}$ & 5 & 41.67 & 13 & 48.15 & 0.742 & 8 & 44.44 & 10 & 47.62 & 1.000 \\
\hline & $\mathrm{CC}$ & 0 & 0.00 & 2 & 7.41 & 1.000 & 0 & 0.00 & 2 & 9.52 & 0.490 \\
\hline & G & 19 & 79.17 & 37 & 68.52 & 0.420 & 28 & 77.78 & 28 & 66.67 & 0.321 \\
\hline & C. & 5. & 20.83 & 17 & 31.48 & 0.420 & 8 & 22.22 & 14 & 33.33 & 0.321 \\
\hline IL10 & $\mathrm{CC}$ & 5 & 41.67 & 14 & 51.85 & 0.731 & 8 & 44.44 & 11 & 52.38 & 0.751 \\
\hline rs1800872 & $\mathrm{CA}$ & 6 & 50.00 & 9 & 33.33 & 0.478 & 9 & 50.00 & 6 & 28.57 & 0.203 \\
\hline & $A A$ & 1 & 8.33 & 4 & 14.81 & 1.000 & 1 & 5.56 & 4 & 19.05 & 0.349 \\
\hline & $C$ & 16 & 66.67 & 37 & 68.52 & 1.000 & 25 & 69.44 & 28 & 66.67 & 0.813 \\
\hline & A & 8 & 33.33 & 17 & 31.48 & 1.000 & 11 & 30.56 & 14 & 33.33 & 0.813 \\
\hline MIF & $\mathrm{GG}$ & 6 & 50.00 & 15 & 55.56 & 1.000 & 10 & 55.56 & 11 & 52.38 & 1.000 \\
\hline rs755622 & $\mathrm{GC}$ & 5 & 41.67 & 11 & 40.74 & 1.000 & 6 & 33.33 & 10 & 47.62 & 0.516 \\
\hline & $\mathrm{CC}$ & 1 & 8.33 & 1 & 3.70 & 0.526 & 2 & 11.11 & 0 & 0.00 & 0.206 \\
\hline & $\mathrm{G}$ & 17 & 70.83 & 41 & 75.93 & 0.779 & 26 & 72.22 & 32 & 76.19 & 0.796 \\
\hline & C & 7 & 29.17 & 13 & 24.07 & 0.779 & 10 & 27.78 & 10 & 23.81 & 0.796 \\
\hline CTLA4 & $\mathrm{GG}$ & 5 & 41.67 & 11 & 40.74 & 1.000 & 8 & 44.44 & 8 & 38.10 & 0.752 \\
\hline rs3087243 & $\mathrm{GA}$ & 6 & 50.00 & 16 & 59.26 & 0.730 & 9 & 50.00 & 13 & 61.90 & 0.528 \\
\hline & AA & 1 & 8.33 & 0 & 0.00 & 0.308 & 1 & 5.56 & 0 & 0.00 & 0.462 \\
\hline & G & 16 & 66.67 & 38 & 70.37 & 0.794 & 25 & 69.44 & 29 & 69.05 & 1.000 \\
\hline & A & 8 & 33.33 & 16 & 29.63 & 0.794 & 11 & 30.56 & 13 & 30.95 & 1.000 \\
\hline NFKB1 & II & 6 & 50.00 & 4 & 14.81 & 0.043 & 8 & 44.44 & 2 & 9.52 & 0.025 \\
\hline rs28362491 & ID & 5 & 41.67 & 15 & 55.56 & 0.501 & 6 & 33.33 & 14 & 66.67 & 0.056 \\
\hline & DD & 1 & 8.33 & 8 & 29.63 & 0.228 & 4 & 22.22 & 5 & 23.81 & 1.000 \\
\hline & I & 17 & 70.83 & 23 & 42.59 & 0.028 & 22 & 61.11 & 18 & 42.86 & 0.119 \\
\hline & D & 7 & 29.17 & 31 & 57.41 & 0.028 & 14 & 38.89 & 24 & 57.14 & 0.119 \\
\hline PADI4 & $\mathrm{GG}$ & 3 & 25.00 & 7 & 25.93 & 1.000 & 4 & 22.22 & 6 & 28.57 & 0.726 \\
\hline rs2240336 & GA & 7 & 58.33 & 17 & 62.96 & 1.000 & 11 & 61.11 & 13 & 61.90 & 1.000 \\
\hline & $A A$ & 2 & 16.67 & 3 & 11.11 & 0.634 & 3 & 16.67 & 2 & 9.52 & 0.647 \\
\hline & G & 13 & 54.17 & 31 & 57.41 & 0.809 & 19 & 52.78 & 25 & 59.52 & 0.648 \\
\hline & A & 11 & 45.83 & 23 & 42.59 & 0.809 & 17 & 47.22 & 17 & 40.48 & 0.648 \\
\hline PTPN22 & GG & 10 & 83.33 & 19 & 70.37 & 0.693 & 14 & 77.78 & 15 & 71.43 & 0.726 \\
\hline rs2476601 & GA & 2 & 16.67 & 7 & 25.93 & 0.693 & 4 & 22.22 & 5 & 23.81 & 1.000 \\
\hline & AA & 0 & 0.00 & 1 & 3.70 & 1.000 & 0 & 0.00 & 1 & 4.76 & 1.000 \\
\hline & G & 22 & 91.67 & 45 & 83.33 & 0.487 & 32 & 88.89 & 35 & 83.33 & 0.533 \\
\hline & A & 2 & 8.33 & 9 & 16.67 & 0.487 & 4 & 11.11 & 7 & 16.67 & 0.533 \\
\hline
\end{tabular}

Statistically significant results are in bold. Abs., absolute values; Freq., frequencies. 


\section{Genetic predictors of the insufficient response to etanercept}

It was shown, that the IL2RA rs2104286*AA genotype was significantly more common, while the IL2RA rs2104286*AG genotype and the IL2RA rs $2104286^{*} G$ allele were significantly less common in JIA patients with the insufficient response to etanercept, than in those with the sufficient response (*AA: $\mathrm{p}=0.011, \mathrm{p}_{\text {cor }}=0.010, \mathrm{OR}=12.75,95 \% \mathrm{Cl} 1.84-146.67 ;{ }^{*} \mathrm{AG}: \mathrm{p}=0.049$, $p_{\text {cor }}=0.049, O R=0.12,95 \% \mathrm{Cl} 0.01-0.88 ;{ }^{*} \mathrm{G}: \mathrm{p}=0.004, \mathrm{p}_{\text {cor }}=0.005$, $\mathrm{OR}=0.08,95 \% \mathrm{Cl} 0.01-0.53$ ) (Table 1). The log-additive model described the results better than the others $(2 \mathrm{GG}+\mathrm{AG}$ vs. $A A$, $\mathrm{p}=0.0037, \mathrm{OR}=0.09,95 \% \mathrm{Cl} 0.01-0.81$ ).

Analysis of the NFKB1 rs28362491 polymorphism revealed a significant increase of the NFKB1 rs28362491*II genotype proportion, and a trend towards a decrease of the NFKB1 rs28362491*ID genotype proportion in JIA patients who did not achieve clinical remission on medication (on etanercept), compared with those who achieved $\left(* I I: p=0.025, p_{c o r}=0.026\right.$, $\mathrm{OR}=7.60,95 \% \mathrm{Cl} 1.53-38.68$ and *ID: $\left.\mathrm{p}=0.056, \mathrm{p}_{\text {cor }}=0.054\right)$ (Table 1). The best inheritance model was the dominant (ID+DD vs. II, $\mathrm{p}=0.011$, OR=0.13, 95\% Cl 0.02-0.74).

At the same time, for the other SNPs no significant differences were observed $\left(p_{\text {cor }}>0,05\right)$. Only testing the inheritance models revealed a trend towards the presence of an effect, that increases the risk of the insufficient response to etanercept, in the IL1B rs16944*T allele (log-additive model, $2 T T+C T$ vs. CC, $p=0.063$ ) and the MIF rs $755622^{*} \mathrm{CC}$ genotype (recessive model, CC vs. GG+GC, $\mathrm{p}=0.073$ ).

\section{Discussion}

The analysis of the association between the polymorphic variants of the immune response mediator genes and the efficacy of the etanercept therapy in JIA patients was performed in this study. The predictors of the increased risk of the non-response to etanercept were the IL1B rs16944*TT ( $\left.p_{\text {cor }}=0.023\right), N F K B 1$ rs28362491*II ( $\left.p_{\text {cor }}=0.042\right)$ genotypes, and of the increased risk of the insufficient response to etanercept - the IL2RA rs2104286*AA $\left(\mathrm{p}_{\text {cor }}=0.010\right), N F K B 1 \mathrm{rs} 28362491 * \mathrm{ll}\left(\mathrm{p}_{\mathrm{cor}}=0.026\right)$ genotypes. The markers of the decreased risk of the non-response to etanercept were the IL1B rs $16944^{*} \mathrm{C}\left(\mathrm{p}_{\mathrm{cor}}=0.046\right), N F K B 1 \mathrm{rs} 28362491^{*} \mathrm{D}$ $\left(p_{\text {cor }}=0.029\right)$ alleles, and of the decreased risk of the insufficient response to etanercept - the IL2RA rs2104286*AG genotype $\left(p_{\text {cor }}=0.049\right)$, IL2RA rs $2104286 * G$ allele $\left(p_{\text {cor }}=0.005\right)$.

According to the literature, the association of only the TNFA rs1800629 locus polymorphic variants was previously investigated with the etanercept efficacy in JIA. Schmeling $H$. and Horneff G. (2007) showed that the TNFA rs1800629*GG genotype serves as a protective marker in relation to non-achieving the ACR Pedi 30 response to etanercept in patients with rheumatoid factor negative polyarticular JIA, but not in the entire JIA group [21]. According to Basic J. et al. (2010), the ACR Pedi 50 response in a year after the etanercept initiation was observed significantly more frequent in polyarticular JIA course patients with the TNFA rs $1800629^{*} G$ genotype, than in those with the TNFA rs1800629*AA genotype, but not with the TNFA rs1800629*A allele generally [22]. Cimaz R. et al. (2007) did not find the relationship of the TNFA rs 1800629 locus polymorphic variants with achieving the ACR Pedi 30 response to TNF $\alpha$ inhibitors as a whole (infliximab, etanercept, adalimumab) in JIA patients [23]. These data are consistent with the results of the present work, where no association of the TNFA rs1800629 locus polymorphic variants with the response to the etanercept therapy in the entire JIA group was found. Nevertheless, Hong Y. and Wang R. (2016) showed, that the frequency of the TNFA rs $1800629 * \mathrm{GG}$ genotype was significantly increased in Chinese JIA patients achieved the ACR Pedi 50 response with the etanercept therapy [24].

It should be noted, that according to Sode J. et al. (2014), the NFKB1 rs28362491*D allele serves as a protective marker in relation to the non-response (European League Against Rheumatism (EULAR) criteria) to etanercept in seropositive rheumatoid arthritis patients from Denmark [25]. In addition, Gębura K. et al. (2017) showed, that the presence of the homozygous genotype NFKB1 rs28362491*II was associated with the increased risk of the non-response (EULAR criteria) to TNF $\alpha$ inhibitors (as a whole), whereas the presence of the NFKB1 rs28362491*D allele, and in particular the NFKB1 rs28362491*ID genotype, - with a higher efficacy of this treatment in rheumatoid arthritis patients from Poland [26]. The results of the current work also indicate, that the NFKB1 rs28362491*D allele reduces the risk of non-achieving the ACR Pedi 70 response to etanercept in JIA patients.

\section{Conclusion}

In this study the association of the alleles and genotypes of the IL1B rs16944, IL2RA rs2104286, NFKB1 rs28362491 polymorphic loci with the etanercept efficacy in JIA patients was established.

\section{Acknowledgments}

The work was supported by:

i) Government project: "Study of molecular genetic mechanisms of formation of multifactorial pathology", No. 115060810015 (08 June 2015).

ii) Grant of the Republic of Bashkortostan to young scientists and youth scientific teams, contract No. 6 (25 March 2016).

iii) The program "Participant of the Youth Scientific and Innovation Contest" ("UMNIK"), contracts No. 10/16859 (28 May 2012) and No. 10/20810 (01 July 2013).

Conflict of interest: none declared.

Ethical approval: All procedures performed in studies involving human participants were in accordance with the standards of the Local ethical committee of Bashkir State Medical University (Ufa, Russia) and with the 1964 Helsinki declaration and its later amendments or comparable ethical standards.

\section{References}

1. Berard RA, Laxer RM. Etanercept (Enbrel) in the treatment of juvenile idiopathic arthritis. Expert Opin Biol Ther 2013; 13(11): 1623-1630. https://dx.doi.org/10.1517/14712598.2013.840580.

2. Ravelli A, Martini A. Juvenile idiopathic arthritis. Lancet 2007; 369: 767-778. https://dx.doi.org/10.1016/S0140-6736(07)60363-8.

3. Petty RE, Southwood TR, Manners P, Baum J, Glass DN, Goldenberg J, et al. International League of Associations for Rheumatology classification of juvenile idiopathic arthritis: second revision, Edmonton, 2001. J Rheumatol 2004; 31(2): 390-392. https://www.ncbi.nlm.nih.gov/pubmed/14760812.

4. Law M, Hanna S, Anaby D, Kertoy M, King G, Xu L. Health-related quality of life of children with physical disabilities: a longitudinal study. BMC Pediatrics 2014; 14: 26. https://dx.doi.org/10.1186/1471-2431$\underline{14-26 .}$. 
5. van Dijkhuizen EH, Wulffraat NM. Early predictors of prognosis in juvenile idiopathic arthritis: a systematic literature review. Ann Rheum Dis 2015; 74(11): 1996-2005. https://dx.doi.org/10.1136/annrheumdis2014-205265.

6. Wallace CA, Giannini EH, Spalding SJ, Hashkes PJ, O'Neil KM, Zeft AS, et al. Trial of early aggressive therapy in polyarticular juvenile idiopathic arthritis. Arthritis Rheum 2012; 64(6): 2012-2021. https://dx.doi.org/10.1002/art.34343.

7. Beukelman T, Patkar NM, Saag KG, Tolleson-Rinehart S, Cron RQ, DeWitt EM, et al. 2011 American College of Rheumatology recommendations for the treatment of juvenile idiopathic arthritis: initiation and safety monitoring of therapeutic agents for the treatment of arthritis and systemic features. Arthritis Care Res (Hoboken) 2011; 63(4): 465-482. https://dx.doi.org/10.1002/acr.20460.

8. Albarouni M, Becker I, Horneff G. Predictors of response to methotrexate in juvenile idiopathic arthritis. Pediatr Rheumatol Online J 2014; 12: 35. https://dx.doi.org/10.1186/1546-0096-12-35.

9. Grom AA, Murray KJ, Luyrink L, Emery $H$, Passo MH, Glass DN, et al. Patterns of expression of tumor necrosis factor alpha, tumor necrosis factor beta, and their receptors in synovia of patients with juvenile rheumatoid arthritis and juvenile spondylarthropathy. Arthritis Rheum 1996; 39(10):

1703-1710. https://www.ncbi.nlm.nih.gov/pubmed/8843861.

10. Prahalad S, Glass DN. A comprehensive review of the genetics of juvenile idiopathic arthritis. Pediatr Rheumatol Online J 2008; 6: 11. https://dx.doi.org/10.1186/1546-0096-6-11.

11. Hahn YS, Kim JG. Pathogenesis and clinical manifestations of juvenile rheumatoid arthritis. Korean J Pediatr 2010; 53(11): 921-930. https://dx.doi.org/10.3345/kjp.2010.53.11.921.

12. Lin $\mathrm{YT}$, Wang $\mathrm{CT}$, Gershwin ME, Chiang BL. The pathogenesis of oligoarticular/polyarticular vs systemic juvenile idiopathic arthritis. Autoimmun Rev 2011; 10(8): 482-489. https://dx.doi.org/10.1016/j.autrev.2011.02.001.

13. Giannini EH, Ruperto N, Ravelli A, Lovell DJ, Felson DT, Martini A. Preliminary definition of improvement in juvenile arthritis. Arthritis Rheum 1997; 40(7): 1202-1209. https://dx.doi.org/10.1002/15290131(199707)40:7\&lt;1202::AID-ART3\&gt;3.0.CO;2-R.

14. Wallace $C A$, Giannini EH, Huang $B$, Itert $L$, Ruperto N. American College of Rheumatology provisional criteria for defining clinical inactive disease in select categories of juvenile idiopathic arthritis. Arthritis Care Res (Hoboken) 2011; 63(7): 929-936. https://dx.doi.org/10.1002/acr.20497.

15. Wallace CA, Ruperto N, Giannini EH. Preliminary criteria for clinical remission for select categories of juvenile idiopathic arthritis. J Rheumatol 2004; 31: 2290-2294. https://www.ncbi.nlm.nih.gov/pubmed/15517647.

16. Mathew CG. The isolation of high molecular weight eukaryotic DNA. Methods Mol Biol 1985; 2: 31-34. https://dx.doi.org/10.1385/0-89603064-4:31.

17. Fagerland MW, Lydersen S, Laake P. Recommended confidence intervals for two independent binomial proportions. Stat Methods Med Res 2015; 24(2): 224-254. https://dx.doi.org/10.1177/0962280211415469.

18. Solé $X$, Guinó $E$, Valls J, Iniesta R, Moreno V. SNPStats: a web tool for the analysis of association studies. Bioinformatics 2006; 22(15): 19281929. https://dx.doi.org/0.1093/bioinformatics/btl268.

19. Westfall PH, Young SS. Resampling-Based Multiple Testing: Examples and Methods for p-Value Adjustment. New York: Wiley, 1993.

20. Liu K, Muse SV. PowerMarker: an integrated analysis environment for genetic marker analysis. Bioinformatics 2005; 21(9): 2128-2129. https://dx.doi.org/10.1093/bioinformatics/bti282.

21. Schmeling $H$, Horneff $G$. Tumour necrosis factor alpha promoter polymorphisms and etanercept therapy in juvenile idiopathic arthritis. Rheumatol Int 2007; 27(4): 383-386. https://dx.doi.org/10.1007/s00296006-0208-2.

22. Basic J, Pavlovic D, Jevtovic-Stoimenov T, Vojinovic J, Susic G, Stojanovic I, et al. Etanercept reduces matrix metalloproteinase-9 level in children with polyarticular juvenile idiopathic arthritis and TNFalpha-308GG genotype. J Physiol Biochem 2010; 66(2): 173-180. https://dx.doi.org/10.1007/s13105-010-0022-x.

23. Cimaz R, Cazalis MA, Reynaud C, Gerloni V, Zulian F, Biggioggero M, et al. IL1 and TNF gene polymorphisms in patients with juvenile idiopathic arthritis treated with TNF inhibitors. Ann Rheum Dis 2007; 66(7): 900-904. https://dx.doi.org/10.1136/ard.2006.067454.

24. Hong $Y$, Wang $R$. The potential of TNF and TNFRSF1B gene polymorphism in predicting the clinical response of anti-TNF therapy in patients with juvenile idiopathic arthritis. Int J Clin Exp Pathol 2016; 9(11): 11936-11943. http://www.ijcep.com/files/ijcep0038796.pdf.

25. Sode J, Vogel U, Bank S, Andersen PS, Thomsen MK, Hetland ML, et al. Anti-TNF treatment response in rheumatoid arthritis patients is associated with genetic variation in the NLRP3-inflammasome. PLoS One 2014; 9(6): e100361. https://dx.doi.org/10.1371/journal.pone.0100361.

26. Gębura K, Świerkot J, Wysoczańska B, Korman L, Nowak B, Wiland P, Bogunia-Kubik K. Polymorphisms within genes involved in regulation of the NF-KB pathway in patients with rheumatoid arthritis. Int J Mol Sci 2017; 18(7): E1432. https://doi.org/10.3390/ijms18071432.

\section{Authors:}

Liliia Sh. Nazarova - MD, Assistant, Department of Therapy and Clinical Pharmacology, Institute of Postgraduate Education, Bashkir State Medical University, Ufa, Russia. http://orcid.org/0000-0002-9666-5650.

Ksenia V. Danilko - PhD, Associate Professor of the Department of Biology, Senior Researcher of the Central Research Laboratory, Bashkir State Medical University, Ufa, Russia. http://orcid.org/0000-0002-4374-2923.

Viktor A. Malievsky - MD, DSc, Professor, Head of the Department of Hospital Pediatrics, Bashkir State Medical University, Ufa, Russia. http://orcid.org/0000-0003-0522-7442.

Akhat B. Bakirov - MD, DSc, Professor, Academician of Academy of Sciences of the Republic of Bashkortostan, Head of the Department of Therapy and Clinical Pharmacology, Institute of Postgraduate Education, Bashkir State Medical University; Director, Ufa Research Institute of Occupational Health and Human Ecology, Ufa, Russia. http://orcid.org/0000-0003-3510-2595.

Tatiana V. Viktorova - MD, DSc, Professor, Head of the Department of Biology, Bashkir State Medical University; Chief Researcher, Laboratory of Physiological Genetics, Institute of Biochemistry and Genetics, Ufa, Russia. http://orcid.org/0000-0001-8900-2480. 